\title{
Unforgiving Heat Wave Deaths in the Largest Metropolitan City of Pakistan: Lessons Learned
}

\author{
Muhammad Akbar Baig', Shahan Waheed', Asad Mian², Erfaan Hussain ${ }^{3}$ \\ 'Department of Emergency Medicine, Aga Khan University Hospital, Karachi, Pakistan \\ 2Department of Emergency Medicine, Pediatrics and Child Health, Aga Khan University Hospital, Karachi, Pakistan \\ ${ }^{3}$ Department of Adult Critical Care Services, Aga Khan University Hospital, Karachi, Pakistan
}

\begin{abstract}
Heat stroke is a deadly condition that needs astute care and timely management. Recently, the city of Karachi in Pakistan has been the victim of an intense heat wave, which has resulted in an insurmountable loss of life. We observed various deficiencies in dealing with this national threat that provides us with a valuable lesson regarding the measures that can be undertaken to avoid such a disaster from occurring again. (Eurasian J Emerg Med 2015; 14: 209-10)

Keywords: Heat stroke, heat wave, emergency, Pakistan
\end{abstract}

Heatstroke is a form of hyperthermia that can result in a systemic inflammatory response leading to multi-organ dysfunction in which encephalopathy tends to predominate (1). It is an acute life-threatening emergency with cardinal features of hyperthermia $\left[>40^{\circ} \mathrm{C}\left(>104^{\circ} \mathrm{F}\right)\right]$ and altered mental status. The mechanism of heatstroke includes direct tissue injury and cell death resulting from cytotoxicity and delayed organ dysfunction because of the activation of inflammatory and coagulation pathways. Histopathological changes include endothelial injury, disseminated intravascular thrombosis, neutrophil infiltration, and apoptosis (2). Populations at high risk include the elderly ( $>75$ years of age), young children ( $<4$ years), persons with limited mobility, alcoholics, and those using antipsychotics, sedative-hypnotics, anticholinergics, antiparkinson medications, and cardiovascular medications (beta-blockers, calcium channel blockers, and vasodilators) (3). Mortality rates are as high as $30 \%-80 \%$ (4) with universal fatality if the condition is left untreated. The goals of therapy are immediate cooling and support of organ function. Physical methods of cooling are recommended such as evaporative cooling, ice water immersion, placement of ice packs to the axilla and groin, cold water gastric and bladder irrigation, peritoneal lavage, and cold IV saline infusion. With any of the above mentioned cooling methods employed separately or in combination, the primary goal is to reduce the core body temperature to $39^{\circ} \mathrm{C}\left(102.2^{\circ} \mathrm{F}\right)$ and then to stop the reduction in the body temperature to avoid overshoot hypothermia (5).
A heat wave is defined as 3 consecutive days of sustained temperatures increasing to $>32.2^{\circ} \mathrm{C}\left(>90^{\circ} \mathrm{F}\right)$. Karachi, a metropolitan city located at the coast, has a relatively mild climate mainly comprising the following two seasons: summer and winter. Summer season persists for the longest period during the year. Recently, in the last week of June 2015, Karachi was held hostage by a particularly intense and prolonged heat wave that ended up claiming hundreds of lives; in the process, another deficiency was exposed in the already under-developed and under-resourced health care infrastructure of Pakistan. Approximately, 1200 people died as a result of the severe 3-day heat wave with the highest number of deaths being observed at the largest government hospital in Karachi, i.e., the Jinnah Post Graduate Medical College (JPMC). Other major hospitals in the city including Abbassi Shaheed Hospital (ASH), Civil Hospital, Liaquat National Hospital (LNH), and Aga Khan University Hospital (AKUH) shared the burden of the remaining cases. The largest charity organization of Pakistan Edhi Welfare stated that two of their city morgues had received $>500$ corpses as a result of death from the heat wave. A possible reason contributing to the large death toll was the fact that at that time, Muslims were observing the Islamic month of Ramadan, during which strict fasting is observed from sunrise to sunset that can amount to significant dehydration, particularly in harsh weather (6).

We observed certain major operational deficiencies while dealing with this recent medical emergency. A majority of these lapses involved deficiencies in standard city-wide operating procedures,

Correspondence to: Muhammad Akbar Baig e-mail:dr_akbar2007@hotmail.com 
untrained medical staff, and unavailability of hospital beds and ventilators. The general public could have been more promptly alerted to the heat wave threat and provided with the necessary precautions earlier, particularly with regard to the sudden and intense climatic change during the holy month of Ramadan. The government could have issued strict instructions for the maintenance of a stable and uninterrupted supply of electricity and water and provided necessary aid to hospitals in preparation for what was an onslaught of heat stroke victims. It is an unfortunate fact that the city hosts approximately 200 ventilators only, which resulted in complete chaos because many hospitals refused to admit sick and/or intubated patients because of the unavailability of intensive care unit beds. This overwhelmed even the major hospitals with heat stroke cases contributing in part to the substantial loss of life.

We believe that this national emergency, like any other, is a necessary reminder of how important it is to continually improve healthcare standards. Mock emergency mass causality drills should be undertaken in major hospitals of the city to keep themselves prepared while dealing with actual natural disasters. Hospitals should be reinforced with proper equipment and strategies for dealing with such situations. Bed capacity should be made available through the setting up of a central government communication center that can facilitate better communication among hospitals so that patient care can remain uninterrupted. Finally, there is an urgent need to educate the affected population regarding self-initiation of first aid cooling strategies, for instance, application of cold water to skin, placement of ice pack to the groin and axilla, cool water shower or immersion, encouraging oral consumption of cold drinks, and seeking proper medical attention. The general public should also be made aware regarding the concept of emergency triage and over use of hospital resources that can result in delays in delivering proper medical attention to deserving patients (7).

Peer-review: Externally peer-reviewed.

Conflict of Interest: No conflict of interest was declared by the authors.

Financial Disclosure: The authors declared that this study has received no financial support.

\section{References}

1. Bouchama A, Knochel J. Heat stroke. N Engl J Med 2002; 346 : 1978-88. [CrossRef]

2. Malamud N, Haymaker W, Custer R. Heatstroke: a clinico-pathologic study of 125 fatal cases. Milit Surg 1946; 99: 397-449.

3. Semenza JC, Rubin CH, Falter KH, Selanikio JD, Flanders WD, Howe HL, et al. Heat-related deaths during the July 1995 heat wave in Chicago. N Engl J Med 1996; 335: 84-90. [CrossRef]

4. Martinez M, Devenport L, Saussy J, Martinez J. Drug-associated heat stroke. South Med J 2002; 95: 799-802. [CrossRef]

5. Bouchama A, Dehbi M, Chaves-Carballo E. Cooling and hemodynamic management in heatstroke: practical recommendations. Crit Care 2007; 11: R54. [CrossRef]

6. DAWN Website: http://www.dawn.com/news/1190983. Published on June 28th , 2015. Accessed: July 7th, 2015.

7. Uscher-Pines, Pines J, Kellermann A. Emergency department visits for nonurgent conditions: systematic literature review. Am J Manag Care 2013; 19: 47-59. 